\title{
Vermicompost significantly affects plant growth. A meta-analysis
}

\author{
Manuel Blouin $^{1}$ D Julien Barrere ${ }^{1} \cdot$ Nicolas Meyer $^{1} \cdot$ Silène Lartigue $^{1} \cdot$ Sébastien Barot $^{2} \cdot$ Jérôme Mathieu $^{2}$
}

Accepted: 17 May 2019 / Published online: 17 June 2019

(C) INRA and Springer-Verlag France SAS, part of Springer Nature 2019

\begin{abstract}
Food production and waste management are two increasing issues ensuing from the growing world population. Recycling organic residues into amendment for food production seems to appear as an opportunity to partially solve this double challenge. Vermicomposting is a process whereby earthworms transform organic residues into compost that can be used as a substrate for plant growth. Many studies have evaluated the effect of vermicompost on plant growth, but a quantitative summary of these studies is still missing. This is the first meta-analysis providing a quantitative summary of the effect size of vermicompost on plant growth. We found that vermicompost brought about average increases of $26 \%$ in commercial yield, $13 \%$ in total biomass, $78 \%$ in shoot biomass, and $57 \%$ in root biomass. The positive effect of vermicompost on plant growth reached a maximum when vermicompost represented 30 to $50 \%$ of the soil volume. The best original material to be used for vermicompost production was cattle manure. The effect was stronger when no fertilizer was added, and lower when the standard Metro-Mix 360 substratum recommended by some authors was used as a growing medium in greenhouse or climatic chambers. Herbs (especially Cucurbitaceae and Asteraceae) and legumes exhibited the largest biomass increase in the presence of vermicompost. These results are discussed through an analysis of potential publication biases showing an over-representation of studies with a high effect size. We finally recommend authors of primary research to provide a minimum set of statistical parameters, output variables, and experimental condition parameters to make it easier to include their work in meta-analyses. Overall, our study provides synthetic information on the beneficial effects of vermicompost for plant growth, which could help bring waste management and agriculture together towards a society with a more circular economy.
\end{abstract}

Keywords Commercial yield $\cdot$ Earthworm-worked soil amendment $\cdot$ Meta-analysis $\cdot$ Plant growth $\cdot$ Vermicompost

\section{Introduction}

Limiting our impact on the environment while feeding an increasing world population is a complex challenge (Godfray et al. 2010). The intensification of farming, based on increasing quantities of mineral fertilizers (Tilman et al. 2001), has led not only to increasing yields but also to the accumulation of phytochemicals in soils and to a global eutrophication of waters (Bennett et al. 2001). In addition, fertilizer shortage is expected in the near future as they are

Manuel Blouin

manuel.blouin@agrosupdijon.fr

1 Agroécologie, AgroSup Dijon, CNRS, INRA, University of Bourgogne Franche-Comté, F-21000 Dijon, France

2 Institute of Ecology and Environmental Sciences of Paris (UMR 7618 IEES-Paris, CNRS, INRA, UPMC, IRD, UPEC), Sorbonne Université, 4 Place Jussieu, 75000 Paris, France produced from non-renewable sources of energy and matter (Vitousek et al. 1997; Edixhoven et al. 2014). The increasing human population and the frequent insufficient connection between the sites of organic waste production (e.g., sewage sludge, animal manure) and crop fields have led to the local accumulation of waste and are responsible for major pollution issues.

Vermicomposting is a process that uses earthworms to transform organic residues into a secondary product named vermicompost (Fig. 1), which can be used as a fertilizer for crop production (Dominguez 2004). Vermicomposting is therefore an interesting solution for both recycling the increasing amount of organic waste and reducing the use of fertilizers. Moreover, the large-scale use of composts is a good way to increase the soil content in organic matter, which is critical for their long-term fertility (Lal 2004; Dignac et al. 2017).

Vermicompost is generally produced by epigeic earthworms (Bouché 1977; Lee 1985) that remain in the litter layer and in the first centimeters of soil and feed on fresh organic matter. Eisenia 
Fig. 1 Organic waste (a) can be processed as vermicompost (b) within ca. 100 days through ingestion and digestion by earthworms such as Eisenia fetida or Eisenia andrei. Photographs: M. Blouin

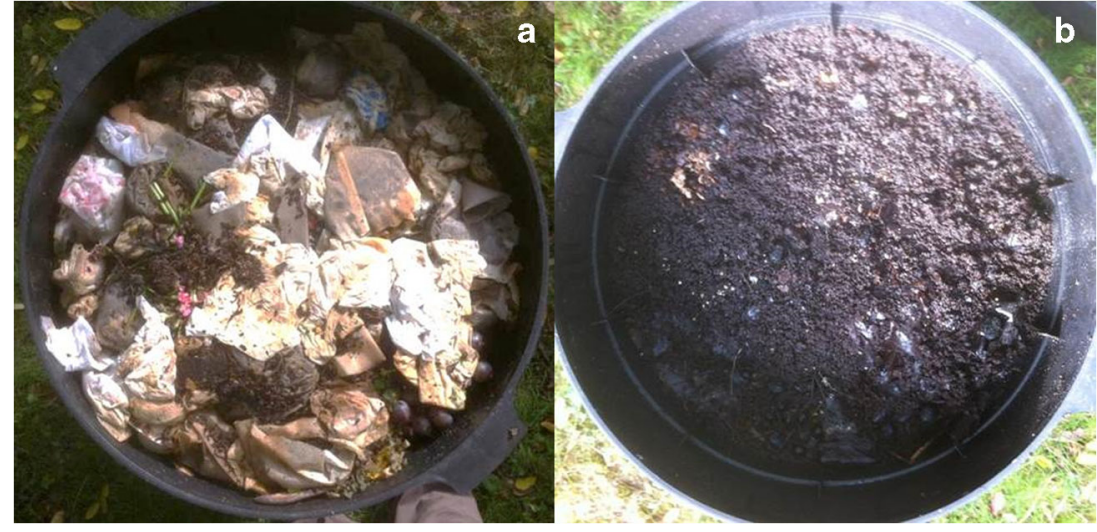

fetida, Savigny (1826) (Haplotaxida, Lumbricidae) and Eisenia andrei, Bouché (1972) (Haplotaxida, Lumbricidae) are the most common species used for vermicomposting because they have high litter ingestion and reproduction rates (Arancon and Edwards 2011). Vermicomposting is a way to benefit from some of the services provided by earthworms (Blouin et al. 2013; Bertrand et al. 2015a) without directly increasing earthworm abundance in soils. In particular, vermicomposting makes it possible to (i) reduce the volume of organic waste, (ii) stabilize organic matter, and (iii) increase plant biomass production through several mechanisms: it increases the soil content in organic matter, which in turn decreases the soil bulk density and increases the availability of water and mineral nutrients, it has hormone-like effects, and it lowers the impacts of pests and pathogens (Edwards et al. 2004). Altogether, vermicomposting is a promising solution for increasing the sustainability of agriculture.

Many studies have evaluated the effect of vermicompost on plant growth. The present study summarizes this literature corpus published over the last 20 years. We performed a meta-analysis to summarize these results and quantify the impact of vermicompost on plant growth. This analysis allowed us to assess the mean impact of vermicompost on plant aboveground and belowground biomass production and to determine the influence of different factors on the size of the vermicompost effect, such as the proportion of vermicompost in the growth medium, the organic material from which the vermicompost was made, and the plant type. This meta-analysis was also an opportunity to identify knowledge gaps and to draw recommendations for future research and the use of vermicompost.

\section{Materials and methods}

\subsection{Literature search}

Publications were searched for in the ISI Web of Science database over the 1997-2016 period using the following key words: "vermicompost" AND "primary production" OR "plant growth" OR "plant production" OR "grain yield” OR "plant biomass" OR "aboveground biomass" OR "belowground biomass" OR "plant yield" OR "role of vermicompost" OR "influence of vermicompost" OR "potential effect of vermicompost." The same search was also performed for the 1997-2010 period, using the Scopus database. Among the 949 references provided by this search, we selected 625 references whose abstracts mentioned the biomass or yield of plants grown in the presence or in the absence of vermicompost. Because many references were published in the gray literature or conference papers, we were only able to retrieve the full text of 394 out of these 625 references. Finally, we selected the articles based on the following information: (i) the presence of a mean value for both a vermicompost (VC) treatment and a control soil without vermicompost $(\mathrm{C})$ for root, shoot, or total biomass values, shoot-root ratio, or commercial yield; (ii) the number of replicates for each treatment; and (iii) a parameter describing the deviation around the average value (variance, standard deviation, or standard error). Only 68 publications met all the criteria for the meta-analysis. During this search, we noted that some studies compared the effect of compost and vermicompost on plant growth (e.g., Jouquet et al. 2010). However, the great majority of studies focused on the comparison of two treatments: a control soil without any organic matter or mineral nutrient added on the one hand and a treated soil with vermicompost added on the other hand. Therefore, our meta-analysis is based on this type of comparison.

\subsection{Data collection}

In the 68 papers providing the above-mentioned information, we identified four output variables: (i) plant total biomass (73 occurrences in 15 publications), (ii) root biomass (212 occurrences in 25 publications), (iii) shoot biomass (245 occurrences in 31 publications), and (iv) commercial yield (122 occurrences in 22 publications). Because of the very scarce data about the effect of vermicompost on the shoot-root ratio 
(13 occurrences in 5 publications), this variable was not analyzed. A total of 665 relevant results were finally extracted.

Several co-variables describing the experimental conditions were also documented: the proportion of vermicompost in the growth medium, the type of experiment (field, greenhouse, climatic chamber), the addition of a mineral fertilizer, and the use of a standard culture medium (Metro-Mix 360, made of vermiculite, bark, and Canadian sphagnum peat moss). To analyze the effect of vermicompost quality, we also retrieved the type of organic matter from which vermicompost was obtained (green waste, urban waste, cattle manure...). Finally, plant characteristics such as the functional type (herb, grass, tree, legume) were also collected.

Other co-variables (e.g., the volume of soil, whether the soil had been sieved, soil bulk density...) were retrieved but did not lead to any statistical analysis either because the number of occurrences of this information was too low $(n<10)$ or because the resulting subgroups were too small $(n<10)$. The following co-variables fell in this category: area/volume of soil, location, temperature, humidity, light intensity, soil origin, whether the soil was sieved, whether a bio-inoculant or a pathogen was added, soil bulk density, texture (sandy/loamy/ clayed), the proportions of carbon, nitrogen, phosphorus, calcium, and magnesium, the $\mathrm{pH}$, the name of the earthworm species, the vermicompost density, elementary composition, age, plant species, family, variety, origin (native/cultivated), biological type (annual/biannual/perennial).

\subsection{Meta-analysis}

\subsubsection{Calculation of effect sizes}

For the four dependent variables characterizing plant growth (total, root, shoot biomass values, yield), we expressed the effect size as a response ratio $(\mathrm{VC} / \mathrm{C})$ because the outcome of the experiments aimed at assessing the impact of vermicompost on plant growth is measured on a physical scale (Borenstein et al. 2009). We used the log response ratio, $\log (\mathrm{VC} / \mathrm{C})$, instead of other metrics such as the standardized mean difference because the outcome of each studied variable was unlikely to be zero (Borenstein et al. 2009) and because it is recommended for a comparison between a treatment and a control in experimental ecology (Hedges et al. 1999). The natural logarithm linearizes the metric, treating deviations in the numerator in the same way as deviations in the denominator, and the sampling distribution of the ratio is skewed, whereas the distribution of $\mathrm{L}$ is much more normal in small samples than that of the ratio (Hedges et al. 1999). The effect size $\left(Y_{i}\right)$ was thus expressed as the logarithm of the response ratio:

$$
Y_{i}=\ln \left(\frac{\text { meanVC }}{\text { meanC }}\right)
$$

We used this ratio to calculate the effect size on plant commercial yield, aboveground biomass, belowground biomass, and total biomass. We were also interested in analyzing the effect of co-variables described in the experimental protocol of each study (e.g., plant type, variation in the soil fertility, use of a fertilizer, climatic conditions) to identify different groups with different effect sizes. To this end, we used a random effects model instead of a fixed effects model. The latter model was designed to compare studies conducted in similar conditions with similar within- and between-study variances, whereas the random effects model accounted for a stronger effect of between-study variance as compared with withinstudy variance in the computation of the global effect size (Borenstein et al. 2009).

To compute the mean effect size $M^{*}$, each individual effect size was weighted with the reciprocal of the sum of the withinstudy variance $\left(V^{*}{ }_{Y i}\right)$ and the estimate of the between-study variance $\left(T^{2}\right)$ (Borenstein et al. 2009).

$M^{*}=\frac{\sum_{i=1}^{n} W_{i} \times Y_{i}}{\sum_{i=1}^{n} W_{i}^{*}}$

with $W_{i}^{*}=1 / V_{Y i}^{*}$

where $V^{*} Y_{i}$ is the within-study variance for study $i V\left(Y_{i}\right)$ plus the between-study variance $T^{2}: V_{Y i}^{*}=V\left(Y_{i}\right)+T^{2}$ where $T^{2}=\frac{Q-d f}{C}$, with $Q=\sum_{i=1}^{k} W_{i} \times Y_{i}^{2} \frac{\left(\sum_{i=1}^{k} W_{i} \times Y_{i}\right)^{2}}{\sum_{i=1}^{k} W_{i}}, \mathrm{df}=k-1$ and $C=\sum W_{i} \frac{\sum W 2_{i}}{\sum W_{i}}$

The variance $V_{M^{*}}$ of the mean effect size $M^{*}$ was then:

$$
V_{M^{*}}=\frac{1}{\sum_{i=1}^{n} W_{i}^{*}}
$$

All figures were based on the log response ratio, and we indicated the percentage of increase or reduction in the vermicompost treatment as compared to the vermicompostfree control and the number of observations used for the test in each figure.

\subsubsection{Subgroup analysis}

We compared the mean effect sizes of the subgroups defined by the different modalities of co-variables listed in Section 2.2. We used a pooled variance estimate $T^{2}$ for all subgroup analyses because we considered that the true between-study variance was likely to be the same for all subgroups (Borenstein et al. 2009). Subgroups were compared using a $Q$ test of heterogeneity, where the measure of heterogeneity was Cochran's $Q$, calculated as the weighted sum of the squared differences between individual study effects and the pooled effect across studies (Cochran 1954). We only considered variables with a sufficient number of observations in each subgroup $(n>10)$ to avoid 
speculative conclusions. Each subgroup analysis was conducted independently from the other, so that there was no integration of the effect of one co-variable when analyzing the effect of a second co-variable.

\subsubsection{Publication bias analysis}

A bias analysis was performed to assess the reliability of the calculated effect sizes. Three approaches were used (Borenstein et al. 2009): (i) the shape of the funnel plots (Light and Pillemer 1984), (ii) correlations between the effect size and the number of replicates, and (iii) Rosenthal and Orwin's fail-safe numbers that estimate the number of missing studies with a mean effect size of zero (or another reference value for Orwin) that should be added to obtain a non-significant difference. All calculations were performed using the MetaWin 2.0 software (Rosenberg et al. 2000).

\section{Results and discussion}

\subsection{Effect of the presence of vermicompost on plant growth}

The addition of vermicompost significantly increased shoot biomass by $78 \%$ and root biomass by $57 \%$ (Fig. 2). These values are higher than the increases in plant biomass following the addition of earthworms (respectively $23 \%$ and $20 \%$ for shoot and root biomass values) found in another meta-analysis (van Groenigen et al. 2014). This difference was likely due to the fact that we studied the impact of adding organic matter that had been processed by earthworms, i.e., vermicompost, while van Groenigen et al. (2014) studied the impact of adding earthworms without adding organic matter. In this latter case, organic matter was supplied as litter to feed epigeic or anecic earthworms or mixed to the soil for endogeic earthworms in both the earthworm and earthworm-free treatments. In our case, we assessed the concomitant impact of the addition of organic matter and of the transformation of this organic matter by epigeic earthworms, and it is recognized that adding organic matter to a growth medium improves soil functioning, with complex but generally positive effects on plant growth (Murphy 2014). This stresses that the compost literature is still focused on demonstrating a beneficial effect of vermicompost but does not seek to analyze the underlying mechanisms precisely or to specifically assess the effect of the processing of organic residues by epigeic earthworms. This also means that, while it is widely acknowledged that adding compost promotes plant growth, whatever the type of compost, at present it is difficult to determine whether vermicomposts are more efficient than other types of composts. To reach this goal, future studies should compare plant growth after adding compost and vermicompost made from the same quantity and quality of organic matter, or conversely after adding amounts of the two compost types adjusted to provide the same amounts of nutrients (e.g., nitrogen or carbon).

Total biomass increased by $13 \%$ in the presence of vermicompost (Fig. 2), which is not consistent with the $57 \%$ and $78 \%$ increases in root and shoot biomass values, respectively. This divergence can be explained by the fact that studies providing root and shoot data were generally

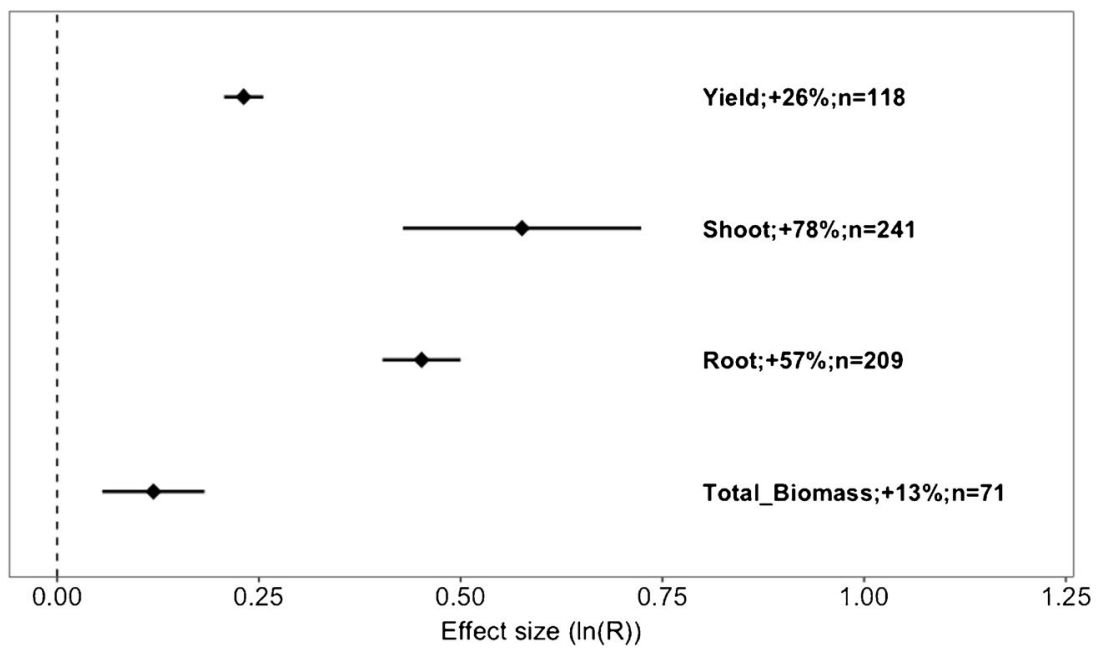

Fig. 2 Effect of vermicompost addition on commercial yield, aboveground (shoot) biomass, belowground (root) biomass, and total biomass of plants. Diamonds correspond to the mean effect size, and horizontal bars to the $95 \%$ confidence interval. A confidence interval that does not overlap the 0 dashed line means that the effect size is significantly different from 0 . The percentage of increase following vermicompost addition and the number of observations are displayed for each variable 
not the same as those providing total biomass data: only $4 \%$ of the analyzed publications provided the three values, and it was not possible to extrapolate the individual total biomass values from the addition of the root and shoot values because these values were averaged.

Plant yield increased by $26 \%$ (Fig. 2) in the presence of vermicompost. Together with the observed increases in plant root, shoot, and total biomass values, the increase in commercial yield suggests that vermicompost is an efficient mean to increase crop yield in agriculture, confirming the results of former non-quantitative reviews (Chaudhary et al. 2004; Lazcano and Domínguez 2011). The use of vermicompost is thought to be particularly useful in organic farming because vermicompost provides nutrients that would otherwise need to be brought by synthetic mineral fertilizers that are prohibited in organic agriculture. However, to be able to fully assess the upsides and downsides of vermicompost for agriculture, other steps are required. (i) It would be important to compare the increase in plant growth attributable to vermicomposts to those attributable to composts produced in the absence of earthworms. (ii) Composting tends to stabilize organic matter, so that composts have long-lasting effects on soil fertility that should be compared between standard composting and vermicomposting. Such a comparison was not possible for us because most vermicomposting studies are shortterm studies. (iii) The economic costs of producing vermicompost and standard compost should be compared.

\subsection{Co-factor analysis}

In this subgroup analysis, we aimed to highlight the effects of (i) the quantitative and qualitative aspects of the vermicompost itself, especially the dose of vermicompost in the growing medium, which greatly varied among studies, and the original material transformed by earthworms, which could present very different initial properties; (ii) the simultaneous use of an inorganic fertilizer in addition to vermicompost; (iii) the plant functional groups, to identify the plants most sensitive to the effect of vermicompost; and (iv) the degree of control of environmental parameters (field, greenhouse, or climatic chamber experiment) or the use of a standard growth substrate called "Metro-Mix 360" that is pushed forward in vermicompost research.

\subsubsection{Effect of the proportion of vermicompost in the growing media}

Vermicompost had a positive effect on shoot biomass for all proportions but $60-80 \%$, but the number of observations was small for that proportion (Fig. 3). The optimal proportion of vermicompost was between 20 and $60 \%$ of the growing medium volume. This proportion is in accordance with the recommendations of many vermicompost producers advising a proportion of $25-50 \%$.

Root biomass significantly increased in the treatments with a proportion of vermicompost ranging between 0 and $60 \%$.

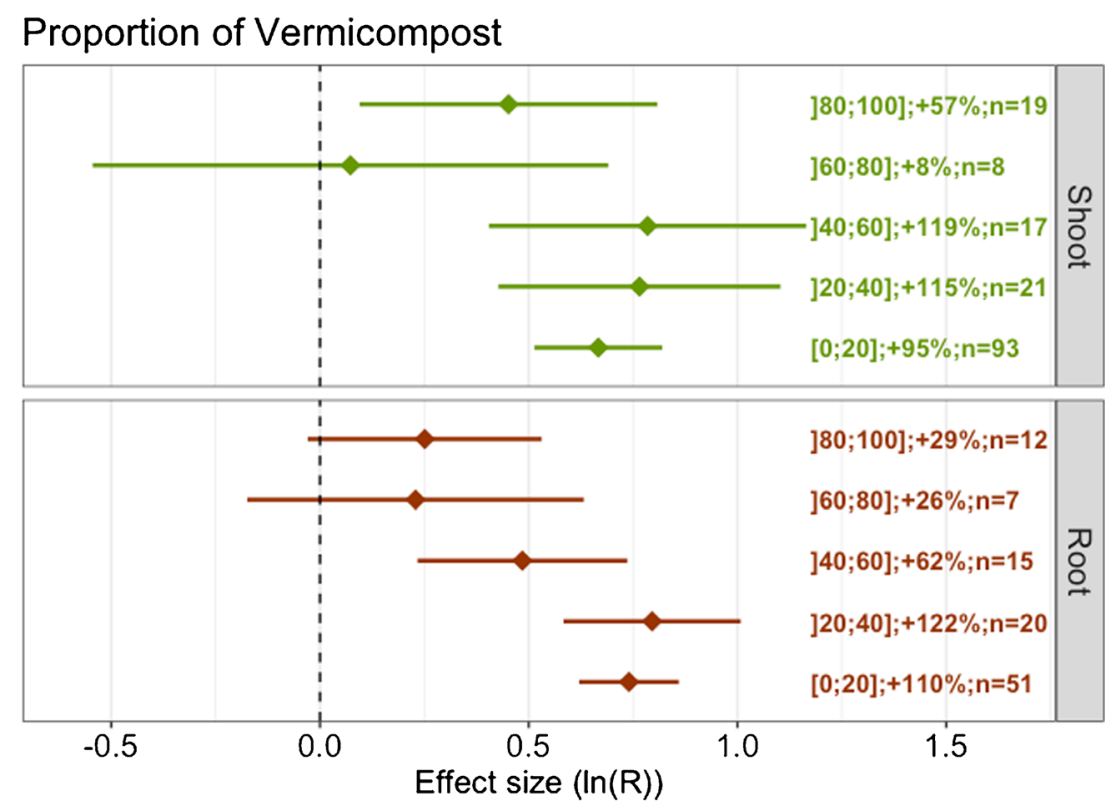

Fig. 3 Influence of the proportion of vermicompost on shoot and root biomass values. Diamonds correspond to the mean effect size and error bars to the $95 \%$ confidence interval; a confidence interval that does not cross the 0 dashed line means that the effect size is significantly different from 0 for a $p$ value of 0.05 . The percentage for each variable represents the conversion of each effect size calculated in the $\ln (R)$ metric ( $x$-axis) into a linear metric, with $R=\mathrm{VC} / \mathrm{C}$ (variable in the vermicompost treatment relatively to the control). $n$ is the number of observations for each variable 
The largest increase in root biomass was obtained with vermicompost proportions between 20 and $40 \%$, as advised by producers. Higher vermicompost proportions (40-60\%) led to a lower positive effect or even $(60-80 \%$ and 80 $100 \%$ ) a disappearance of the significant positive effect on root biomass.

Increasing the proportion of vermicompost could be similar to increasing the density of earthworms. In some cases, earthworm (Aporrectodea caliginosa) density was linearly correlated with the increase in biomass production (Baker et al. 1999), as observed in a meta-analysis of the effects of earthworms on plant growth (van Groenigen et al. 2014). In other cases, the relationship between earthworm density and plant production was curvilinear, with a maximum positive effect on plant growth observed at an intermediate density (Brown et al. 1999; Chan et al. 2004). This last observation is more in accordance with ours. It is still unclear whether the disappearance of the positive effect at high proportions of vermicompost or high abundances of earthworms is due to an overdose of specific compounds such as hormone-like molecules, or to the prevalence of another mechanism with a negative effect on plant growth, such as soil compaction, or too strong competition for nutrients with microorganisms.

\subsubsection{Impact of the original material on the effect of vermicompost}

The original material that provided the highest effect size of vermicompost was cattle manure, with an increase of $27 \%$ in yield, $113 \%$ in shoot biomass, and $88 \%$ in root biomass (Fig. 4). Pig manure was also a good material leading to increases in shoot and root biomass values of 30 and 55\%, respectively. Farms with a breeding activity could take advantage of their organic residues by producing the most efficient vermicompost to increase plant growth. Food waste is also an interesting material that led to a significant increase of $44 \%$ in shoot biomass (Fig. 4), but it had no significant effect on root biomass. This kind of waste is becoming more and more abundant with the concentration of human populations in cities and mass catering. Food waste could be seen as an opportunity to develop vermicomposting, since one quarter of the food produced each year is never consumed (Kummu et al. 2012). Nevertheless, the reduction of food waste is the first objective to achieve, especially with around 108 million people at a high risk of or already facing severe acute food insecurity in 2016 Food Security Information Network (2017).

Paper waste was found more interesting for root growth (+ $55 \%)$ than for shoot growth $(+34 \%)$. The world production of paper has increased at the global scale, with 450 million tons in 2015 and 600 expected in 2030 (Szabo et al. 2009). However, the environmental benefits of paper waste vermicomposting remain questionable as compared to the numerous benefits of recycling, such as the reduction of wood consumption and subsequent landfilling, lower energy needs, and lower water consumption (Bureau of International Recycling (BIR), 2008). For example, recycling 1 ton of paper saves around $682.5 \mathrm{gal}$ of oil, 26,500 1 of water, and 17 trees (http://www.theworldcounts.com/stories/Paper-Waste-Facts). Nowadays, recycling paper is already very common and likely to be more beneficial to the environment than the use of paper in vermicomposting. In addition, this paper material can contain pollutants (e.g., remains of petroleum-derived

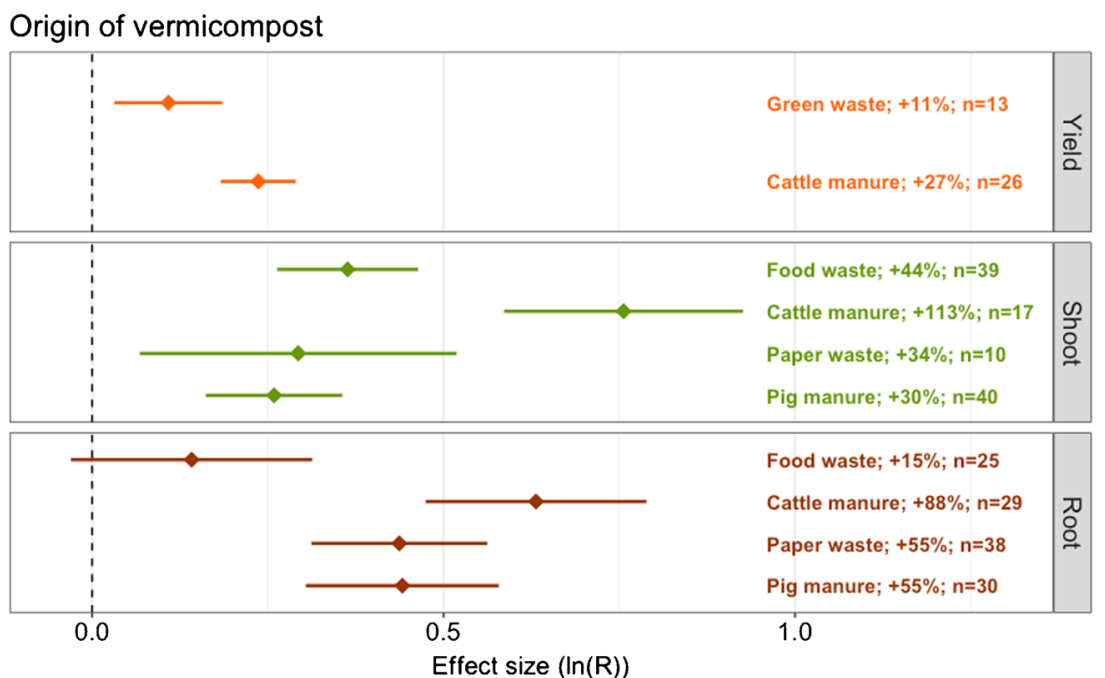

Fig. 4 Influence of the original material on the effect of vermicompost on commercial yield, shoot biomass, and root biomass. Diamonds correspond to the mean effect size and error bars to the $95 \%$ confidence interval; a confidence interval that does not cross the 0 dashed line means that the effect size is significantly different from 0 for a $p$ value of 0.05 .
The percentage for each variable represents the conversion of each effect size calculated in the $\ln (R)$ metric ( $x$-axis) into a linear metric $(R=\mathrm{VC} / \mathrm{C}$, with $\mathrm{VC} / \mathrm{C}$ : variable in the vermicompost treatment relatively to the control). $n$ is the number of observations for each variable 
hydrocarbons or in some cases heavy metals), which could be transferred to plants, and this is particularly undesirable when these plants are used as food.

Taken together, economic, social, and environmental analyses are needed to assess the pros and cons of vermicompost production from manure and food waste and to compare vermicomposting to other alternatives (standard composting, methanization...).

\subsubsection{Impact of mineral fertilizers on the effect of vermicompost}

The addition of vermicompost increased biomass values whatever the mineral fertilization. Nevertheless, mineral fertilization decreased the positive effect of vermicompost addition from 38 to $14 \%$ for the commercial yield, from 134 to $28 \%$ for shoot biomass, and from 72 to $39 \%$ for root biomass (Fig. 5). It is interesting to note that in their meta-analysis of the effects of earthworms on plant growth, van Groenigen et al. (2014) showed that the effect decreased from + 19 to + $9 \%$ and was no longer significantly different from zero when the amount of mineral nitrogen supply exceeded $30 \mathrm{~kg} \mathrm{~N} \mathrm{ha}{ }^{-1}$ year $^{-1}$. These observations converge towards the hypothesis that an increase in the availability of mineral nitrogen (and other mineral nutrients) is partially responsible for the increases in plant biomass when earthworms are present or when vermicompost is added (Lavelle et al. 1992; Aira et al. 2005). Earthworms indeed promote the mineralization of the soil organic matter and litter, and vermicompost is rich in mineral nutrients both in their mineral and organic forms. However, $\mathrm{N}$ mineralization is a necessary but probably not a sufficient mechanism to explain this positive effect of earthworms or vermicompost (Blouin et al. 2006; Laossi et al. 2010). Other concomitant mechanisms could be necessary, such as the emission of signal molecules (Puga-Freitas et al. 2012b) likely to be produced by microorganisms stimulated by earthworms (Puga-Freitas et al. 2012a).

\subsubsection{Impact of vermicompost on the growth of various plant families}

Vermicompost had a positive effect on the commercial yield of all plant families present in our database (even with $n<10$ ), with the strongest effect on Lamiaceae $(n=21,+31 \%)$, Solanaceae $(n=34,+28 \%)$, and Poaceae $(n=50,+15 \%)$ (data not shown). The effect on shoot biomass was family dependent, with a non-significant effect on Brassicaceae $(n=15,+$ $55 \%)$ or Rosaceae $(n=12,+4 \%)$, but with a significant one on Cucurbitaceae $(n=25,+242 \%)$, Fabaceae $(n=22,+$ $164 \%)$, Asteraceae $(n=26,+136 \%)$, Poaceae $(n=15,+$ $128 \%)$, and Solanaceae $(n=113,+42 \%)$. Finally, the root biomass of Poaceae significantly decreased with the addition of vermicompost $(n=15,-30 \%)$, whereas it was nonsignificantly affected in Iridaceae, Brassicaceae, Liliaceae, Musaceae, and Alliaceae, and significantly increased in Cucurbitaceae $(n=10,+182 \%)$, Asteraceae $(n=35,+$ $123 \%)$, Rosaceae $(n=14,+70 \%)$, Fabaceae $(n=13,+$ $61 \%)$, and Solanaceae $(n=96,+48 \%)$. Cucurbitaceae, Asteraceae, and Fabaceae seemed to be the families that responded best to vermicompost in terms of shoot and root biomass values. Other families such as Poaceae exhibited a positive response at the shoot level but a negative one at the root level, together with an overall increase in total biomass; this could indicate an adaptive reallocation of resources

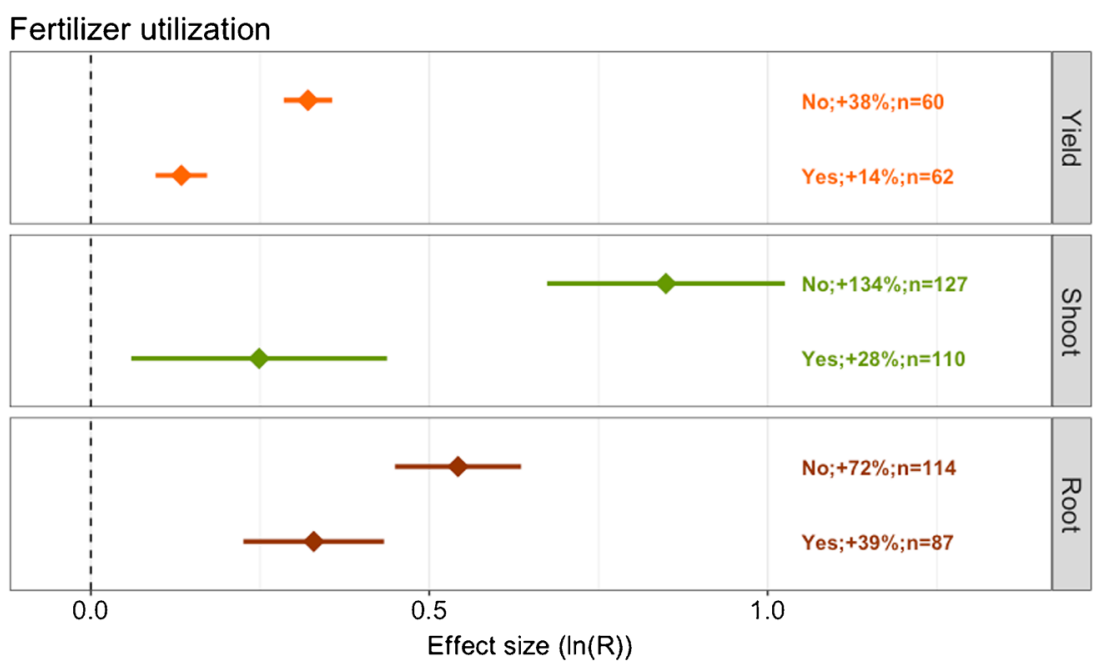

Fig. 5 Influence of the addition of a mineral fertilizer on commercial yield, shoot biomass, and root biomass. Diamonds correspond to the mean effect size and error bars to the $95 \%$ confidence interval; a confidence interval that does not cross the 0 dashed line means that the effect size is significantly different from 0 for a $p$ value of 0.05 . The percentage for each variable represents the conversion of each effect size calculated in the $\ln (R)$ metric ( $x$-axis) into a linear metric. $n$ is the number of observations for each variable (one observation consists of a couple of control and vermicompost treatment values making the calculation of $R=\mathrm{VC} / \mathrm{C}$ possible) 
towards the shoots at the expense of the roots when the limitation of plant growth is alleviated by increased nutrient availability (Wilson 1988). Because the effect of vermicompost is dependent on the plant species, more data are needed about the commercial yield of different plant species to better identify the conditions in which the use of vermicompost by farmers will be most relevant.

\subsubsection{Effect on different plant functional types}

We distinguished between grasses (non-woody annual or perennial plants with a graminoid morphology, including cereals, corresponding to the monocotyledons), trees (defined as woody plants with a trunk), legumes (able to associate with Rhizobium for atmospheric $\mathrm{N}_{2}$ fixation, corresponding to the Fabaceae family), and herbs (the remaining non-woody non-legume dicotyledonous species). Although there was a general positive effect of vermicompost on commercial yield whatever the functional group and on shoot and root biomass for a majority of functional groups, a trend towards a negative effect of vermicompost on the shoot of trees and on the roots of grasses was observed (Fig. 6). The most reliable effect was observed on herbs, with a positive effect on yield and shoot and root biomass, with a high number of observations. Our results are in accordance with the 25 and $32 \%$ increases in aboveground biomass observed for grasses and cereals, respectively, in the presence of earthworms (van Groenigen et al. 2014). However, we found a positive effect of vermicompost $(+163 \%)$ on the shoot biomass of legumes, while van Groenigen et al. (2014) showed that the presence of earthworms (mainly endogeic ones) did not significantly affect the shoot biomass of this functional type. Their meta-analysis mostly addressed endogeic earthworms, whereas epigeic earthworms are the ones commonly used for vermicompost production. This suggests that different earthworm functional groups could act through diverse mechanisms. For example, endogeic earthworms are more prone to modify the soil physical structure than epigeic earthworms, and this could have consequences on water availability or microbial habitats.

\subsubsection{Effect of a standard growth substrate promoted in the literature}

A standard growth medium has been promoted by several authors in recent years, i.e., Metro-Mix 360®, made of Canadian Sphagnum peat moss, vermiculite, bark ash, starter nutrient charge (with gypsum) and slow-release nitrogen, dolomitic limestone, and a long-lasting wetting agent (Sun Gro Horticulture, Agawam, USA). It is important to determine whether this growth medium provides similar results to those obtained in other growth media or to detect a potential bias of this substratum as compared with others. The effect size of vermicompost on shoot biomass was lower in the experiments with Metro-Mix 360 (+ $43 \%)$ than in those with other growing media (+118\%; Fig. 7). However, the effect on root biomass was similar whether with Metro-Mix 360 or with other media (+ $47 \%$ and $+37 \%$, respectively). Although Metro-Mix 360 was supposed to be a standard growing media with a stable composition, the variance of the effect size was similar whether it was used or not (Fig. 7). This similarity in the variance of the effect size could be due to (i) uncontrolled variations in the composition or properties of Metro-Mix 360, (ii) poor homogenization of the vermicompost-Metro-Mix 360 mix, or (iii) the standardization

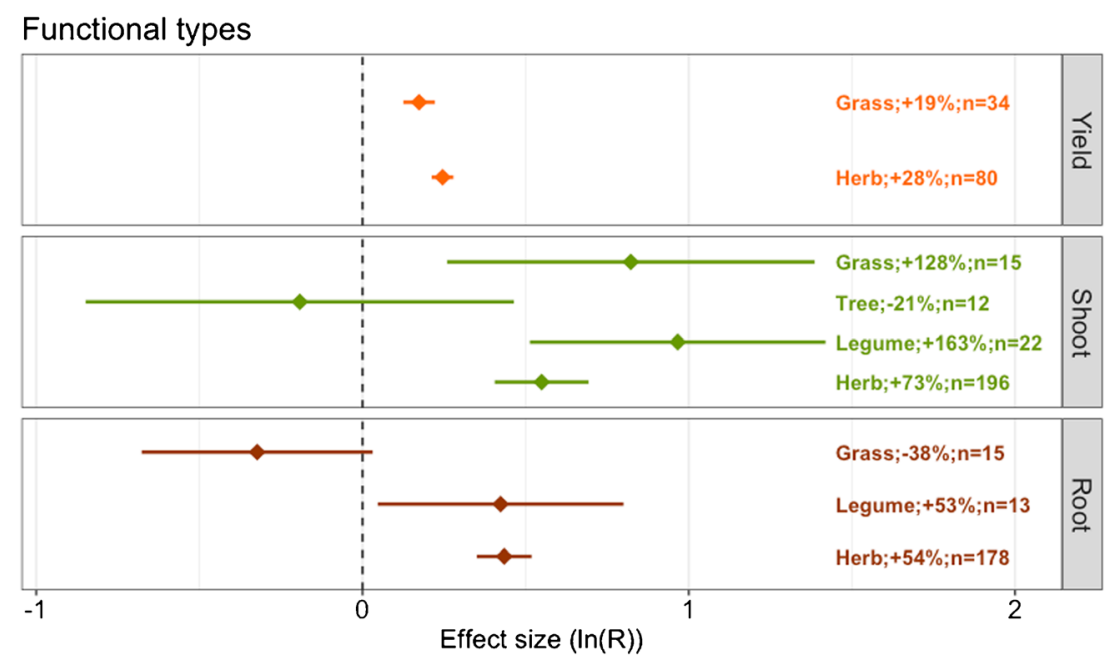

Fig. 6 Responses of the different plant functional types to the presence of vermicompost in terms of commercial yield, shoot biomass, and root biomass. Diamonds correspond to the mean effect size and error bars to the $95 \%$ confidence interval; a confidence interval that does not cross the 0 dashed line means that the effect size is significantly different from 0 for a $p$ value of 0.05 . The percentage for each variable represents the conversion of each effect size calculated in the $\ln (R)$ metric ( $x$-axis) into a linear metric. $n$ is the number of observations for each variable (one observation consists of a couple of control and vermicompost treatment values making the calculation of $R=\mathrm{VC} / \mathrm{C}$ possible) 
Mix360 utilization

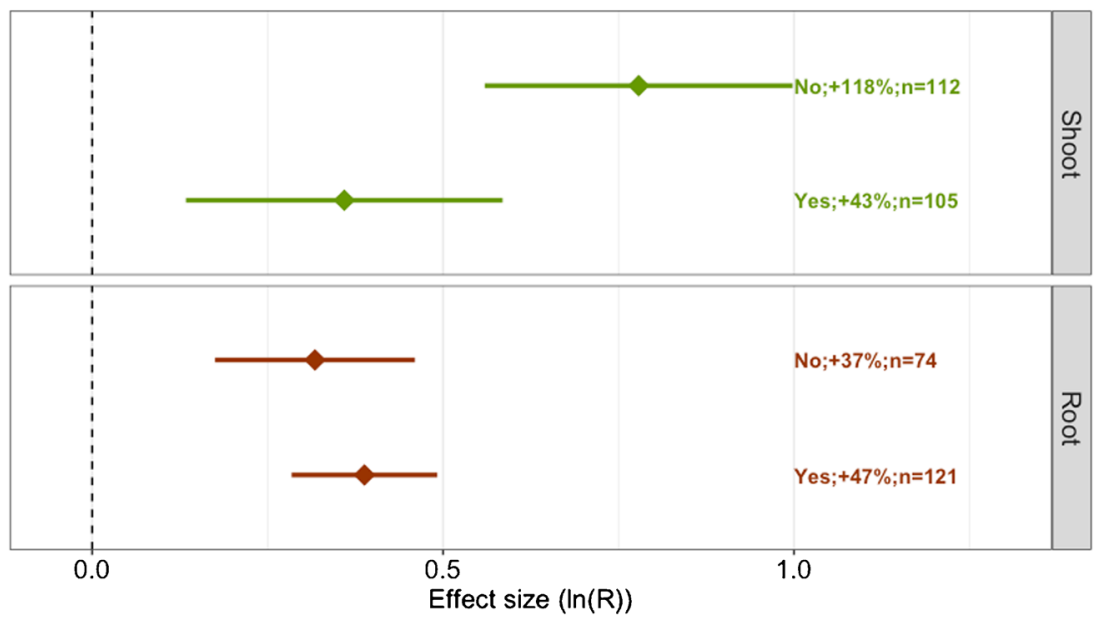

Fig. 7 Influence of the standard culture medium Mix360 on the effect of vermicompost on shoot and root biomass. Bars correspond to the mean effect size and error bars to the $95 \%$ confidence interval; a confidence interval that does not cross the 0 dashed line means that the effect size is significantly different from 0 for a $p$ value of 0.05 . The percentage for

of certain experimental conditions that may have amplified the influence of non-controlled environmental parameters on the variance output variables (Richter et al. 2009; Milcu et al. 2018).

\subsubsection{Effect of the degree of environmental control}

Environmental conditions can strongly differ among experiments and be responsible for a great part of the variance of the vermicompost effect size. Climatic conditions (temperature, humidity, the photoperiod) are believed to be more stable in climatic chambers than in the greenhouse or in the field and could result in less variable effect sizes of the vermicompost effect. Our results invalidate this prediction (Fig. 8), as the highest effect size variance was observed in climatic chambers and resulted in a non-significant effect of vermicompost on root and shoot each variable represents the conversion of each effect size calculated in the $\ln (R)$ metric ( $x$-axis) into a linear metric. $n$ is the number of observations for each variable (one observation consists of a couple of control and vermicompost treatment values making the calculation of $R=$ $\mathrm{VC} / \mathrm{C}$ possible)

biomass values for these experiments despite a high number of observations $(n=43,+27 \%$ and $n=40,+51 \%$ for root and shoot biomass values, respectively). This could be explained by the high variability occurring inside the small volume of a climatic chamber due to the lack of inertia. A lower variance for root and shoot biomass values was observed in the greenhouse, likely due to the high number of observations ( $n=151$ and $n=$ 168 , respectively), since $T^{2}$, the between-study variance, was negatively correlated with $n$ (see Section 2.3.1). Increasing the number of observations in climatic chambers could reduce the total variance and lead to the detection of a significant effect, as in the case of studies in the greenhouse. Nevertheless, this is unlikely to change the average value of the effect size, which was rather low in climatic chambers. In addition, we noted that the effect size on shoot biomass was the strongest in the field (+

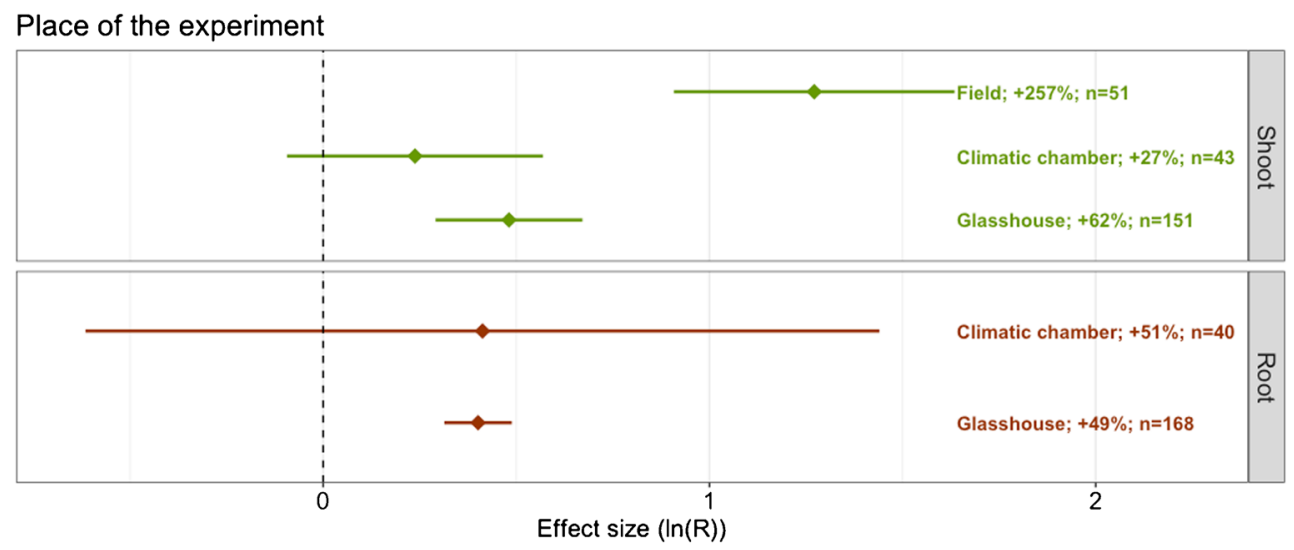

Fig. 8 Influence of the degree of control on experimental conditions on the effect of vermicompost on shoot and root biomass values. Diamonds correspond to the mean effect size and error bars to the $95 \%$ confidence interval; a confidence interval that does not cross the 0 dashed line means that the effect size is significantly different from 0 for a $p$ value of 0.05 .
The percentage for each variable represents the conversion of each effect size calculated in the $\ln (R)$ metric ( $x$-axis) into a linear metric. $n$ is the number of observations for each variable (one observation consists of a couple of control and vermicompost treatment values making the calculation of $R=\mathrm{VC} / \mathrm{C}$ possible) 
$257 \%)$ as compared to the climatic chamber $(+27 \%)$ or the greenhouse $(+62 \%)$. This could be due to the fact that vermicompost is often applied at the soil surface in the field; this localized nutrient supply and the absence of a dilution of vermicompost in the soil could be beneficial to plant development (Drew et al. 1973; Robinson 1994). Another explanation could be that earthworms, like many soil organisms, can improve plant growth via several mechanisms: signal molecules emitted in their presence (Section 3.2.3) can improve both nutrient uptake and disease and pest resistance (Puga-Freitas and Blouin, 2015). As plants are less exposed to pests and diseases in climatic chambers than in greenhouses or in the field, vermicompost could induce a systemic resistance in the field, leading to a greater difference in plant growth between the control and the vermicompost treatment. Considering this mechanism in metaanalyses would require documenting field observations of pests and diseases to perform a subgroup analysis taking this co-factor into account.

\subsection{Publication bias}

A meta-analysis inevitably misses some studies due to the publication and referencing system, the coverage of databases, the algorithms used by search engines, or the choice of keywords. If the effect sizes of the missing studies are randomly distributed, they should not affect the average value of the effect size calculated in the meta-analysis. But if the missing studies have a higher or lower effect size than the average effect size, then the calculated effect size is biased (Borenstein et al. 2009). We retrieved references from the Scopus and Web of Science databases that did not include all the studies published in the gray literature. This could be responsible for a sampling of the literature not fully representative of the whole literature. However, the retrieved references are those available to a large majority of researchers, and it is interesting to determine whether that literature corpus exhibits a publication bias by itself.

When seeking for a publication bias with the different techniques listed in Section 2, we found that three of the four variables we studied were likely to be subject to a publication bias: the funnel plots of the shoot biomass, root biomass, and yield

Table 1 Results of the publication bias analysis based on correlations between the effect size and the number of replicates (Kendall and Spearman correlation coefficients), the number of studies, and the exhibited a truncation for negative effect size values with a poor number of replicates (data not shown). This was confirmed by the significant negative correlation between the effect size and the number of replicates for both coefficients of Kendall and Spearman (Table 1). However, this correlation was low for the shoot and root biomass values $(-0.13$ with a $p$ value of 0.003 and -0.15 with a $p$ value of 0.004 , respectively), but higher for yield ( -0.28 with a $p$ value of 0.00002$)$. Rosenthal's fail-safe number differed between the variables by several orders of magnitude: $10^{4}$ for total biomass, $10^{5}$ for root biomass, $10^{7}$ for shoot biomass, and $10^{8}$ for yield. Orwin's fail-safe number did not provide the same ordering: total biomass $(0.0)<$ yield $(53.8)<$ root biomass $(224.1)<$ shoot biomass (1781.0) (Table 1). We thus observed a lack of publications with low or negative effect sizes together with a low number of replicates. Non-significant studies are less likely to be published than significant studies (14-39\% less) (Borenstein et al. 2009). Because studies with high effect sizes are more likely to find significant effects, there was a publication bias towards a high effect size. This caused a risk of overestimating the effect size, especially for the studies with relatively small sample sizes (Borenstein et al. 2009). As a consequence, the effect sizes calculated for yield and shoot and root biomass values were potentially overestimated, but this was not the case for total biomass.

In the same vein, competition among journals to attract the best papers could result in an increasing bias towards a high effect size when the impact factor of the journal increases. We indeed observed that the highest effect sizes for shoot and root biomass values $(+221 \%$ and $+169 \%$, respectively) were published in the journals with the highest impact factors (between 4 and 5; Fig. 9), and there was a significant difference between the effect sizes observed in this category of journals and those observed in other categories.

\subsection{Recommendations}

\subsubsection{Statistical parameters}

The gap between the 949 publications matching our search and the 68 studies we finally retained $(7 \%)$ was due to (i) non-

number of missing studies (with a mean effect size of zero) that should be added to obtain a non-significant difference (Rosenthal's and Orwin's fail-safe numbers)

\begin{tabular}{|c|c|c|c|c|c|c|c|}
\hline & \multirow[t]{2}{*}{ Number } & \multicolumn{2}{|l|}{ Kendall } & \multicolumn{2}{|c|}{ Spearman } & \multirow[t]{2}{*}{ Rosenthal } & \multirow[t]{2}{*}{ Orwin } \\
\hline & & Tau & $p$ value & $R \mathrm{~s}$ & $p$ value & & \\
\hline Total biomass & 71 & -0.132 & 0.098 & -0.179 & 0.130 & 10,801 & 0 \\
\hline Root biomass & 209 & 0.122 & 0.008 & 0.169 & 0.014 & 17,062 & 168 \\
\hline Shoot biomass & 241 & 0.595 & $<0.00001$ & 0.698 & $<0.00001$ & $16,347,612.7$ & 1783 \\
\hline Yield & 118 & 0.329 & $<0.00001$ & 0.46 & $<0.00001$ & $155,286,798.3$ & 53 \\
\hline
\end{tabular}




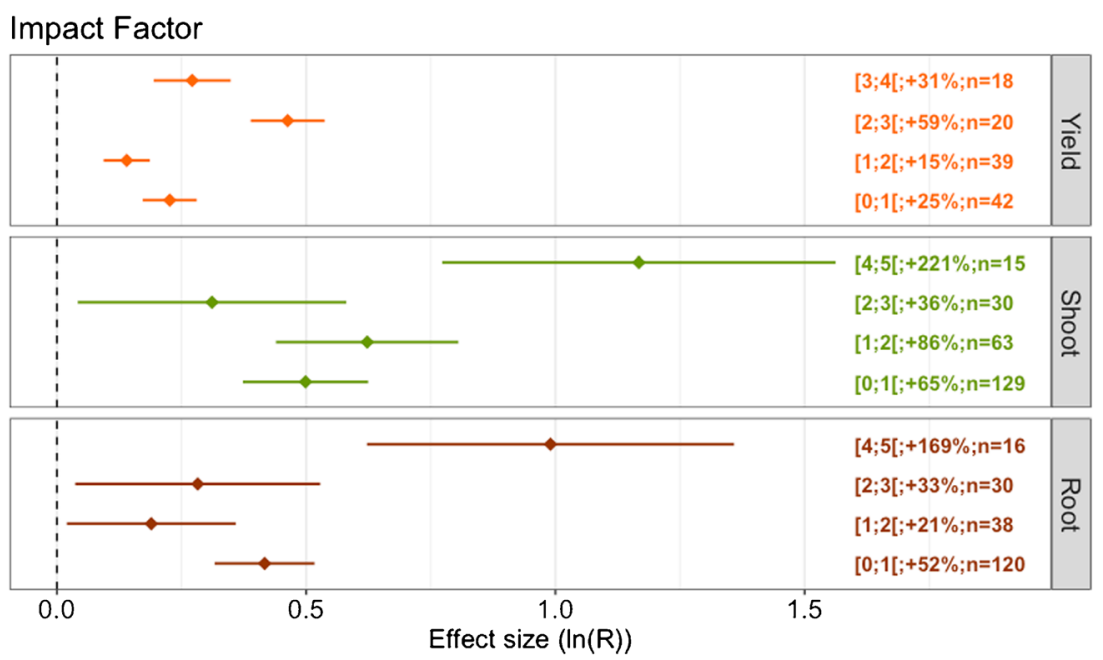

Fig. 9 Influence of the impact factor of journals on the effect of vermicompost on commercial yield and shoot and root biomass. Diamonds correspond to the mean effect size and error bars to the $95 \%$ confidence interval; a confidence interval that does not cross the 0 dashed line means that the effect size is significantly different from 0 for a $p$ value

relevant publications removed after reading the summary (34\%), (ii) the fact that the full text was not available (24\%), and (iii) the absence of minimum required information (35\%). It would be possible to keep more than one third of the initial pool of references if mean values were provided, together with a value describing variations around these means and the number of replicates for both a control and a vermicompost treatment. Therefore, we advocate for the generalized inclusion of such information in all articles.

\subsubsection{Number of measured variables}

The number of output variables reported in a study is also determining because it can help increase the robustness of the results by cross-validation: for example, we found mean effect sizes for shoot $(+78 \%)$ and root $(+57 \%)$ biomass values inconsistent with results obtained for total biomass $(+13 \%)$. This apparent incoherence was easily explained by the fact that the data were retrieved from different studies (only $4 \%$ of the studies provided values for the three variables), making cross-validation between variables impossible. Authors should therefore provide information on shoot, root, and total biomass values, as well as on shoot-root ratios.

\subsubsection{Information on experimental conditions}

The number of studies available for subgroup analyses was sometimes low because experimental conditions were not always well described. In general, the time of exposure to the treatments, the type of soil, its physico-chemical properties, the amount of fertilizer, and the climatic conditions among others were poorly described in many studies. These elements of 0.05 . The percentage for each variable represents the conversion of each effect size calculated in the $\ln (R)$ metric ( $x$-axis) into a linear metric. $n$ is the number of observations for each variable (one observation is a couple of control and vermicompost treatment values making the calculation of $R=\mathrm{VC} / \mathrm{C}$ possible)

should be provided. It would also be very interesting to have more data on the effect of vermicompost when plants are exposed to pathogens or parasites, since biocontrol (Puga-Freitas et al. 2016) or induction of systemic resistance in the presence of earthworms (Blouin et al. 2005; Bertrand et al. 2015b) or vermicompost (Chaoui et al. 2002; Arancon et al. 2005, 2007; Edwards et al. 2010a) have been reported in the literature.

\subsubsection{Efforts in publishing null results}

To avoid the propagation of wrong values of vermicompost effect size, which would arise strong skepticism towards this field of research, we encourage scientists implementing experimental studies on vermicompost to publish all their results, including negative/null and non-significant ones. We also encourage editors of journals to tolerate null results (Rosenthal 1979) and to be careful with exceptionally high effect sizes by asking the publication of rough data.

\section{Conclusions}

We found significant effects of vermicompost on plant biomass production. As compared with a meta-analysis on the effects of earthworms on plant growth (van Groenigen et al. 2014), adding vermicompost led to similar $(+26 \%$ for yield), lower ( $+13 \%$ for total biomass), or higher $(+78 \%$ for shoot biomass and $+57 \%$ for root biomass) increases in biomass values. The best conditions for observing a strong effect of vermicompost on plant growth are the following: a proportion of vermicompost ranging between 30 and $50 \%$ of the volume of the growing medium, cattle manure as original material, the 
absence of a fertilizer, another substratum than Metro-Mix 360 as a growing medium, and field conditions. Cucurbitaceae, Asteraceae, Fabaceae, and Poaceae were the most responsive families. Herbs (dicotyledonous plants other than trees) and legumes (Fabaceae) were the two most responsive functional types.

The amount of organic residues is growing and will continue to grow worldwide. The higher the income level and rate of urbanization, the higher the amount of solid waste produced: OECD countries produce almost half of the world's waste (Hoornweg and Bhada-Tata 2012), and a World Bank study predicts a $70 \%$ global increase in urban solid waste from 1.3 billion tons per year in 2012 to 2.2 billion tons per year by 2025 , with a corresponding rise from $\$ 205$ billion to $\$ 375$ billion for annual global costs (Hoornweg and Bhada-Tata 2012). Within this urban waste, the proportion of organic waste is roughly $20-30 \%$. Recycling circuits could be set up, with vermicomposting as a way to transform organic urban waste into a resource. But as for compost, a major impediment is the lack of a comprehensive assessment of the costs of organic residue collection, handling, and processing that would integrate marketing, distribution, and recycling in a life cycle analysis reflecting external costs and societal benefits (Shiralipour et al. 1992). Finally, general and synthetic knowledge on vermicompost is still missing. We hope that the quantitative summary provided by the present meta-analysis will help bridge this gap.

Acknowledgments We thank Louis Gaetan for an initial analysis and Magalie Aferiat and Solenn Le Guillou who took part in the retrieving of data.

\section{Compliance with ethical standards}

Conflict of interest The authors declare that they have no conflict of interest.

\section{Bibliography}

Aira M, Monroy F, Domínguez J (2005) Ageing effects on nitrogen dynamics and enzyme activities in casts of Aporrectodea caliginosa (Lumbricidae). Pedobiologia 49:467-473. https://doi.org/10.1016/j. pedobi.2005.07.003

Arancon NQ, Edwards CA (2011) The use of vermicomposts as soil amendments for production of field crops. In: Edwards CA, Arancon NQ, Sherman R (eds) Vermiculture technology: earthworms, organic wastes, and environmental management. CRC Press, Boca Raton, pp 129-151

Arancon NQ, Edwards CA, Bierman P et al (2005) Effects of vermicomposts produced from cattle manure, food waste and paper waste on the growth and yield of peppers in the field. Pedobiologia 49:297-306

Arancon NQ, Edwards CA, Yardim EN et al (2007) Suppression of twospotted spider mite (Tetranychus urticae), mealy bug (Pseudococcus $s p$ ) and aphid (Myzus persicae) populations and damage by vermicomposts. Crop Prot 26:29-39. https://doi.org/10.1016/j. cropro.2006.03.013

Baker GH, Carter PJ, Barrett VJ (1999) Influence of earthworms, Aporrectodea spp. (Lumbricidae), on pasture production in SouthEastern Australia. Aust J Agric Res 50:1247-1257

Bennett EM, Carpenter SR, Caraco NF (2001) Human impact on erodable phosphorus and eutrophication : a global perspective. Bioscience 51:227-234

Bertrand M, Barot S, Blouin M et al (2015a) Earthworm services for cropping systems. A review. Agron Sust Dev 35:553-567. https:// doi.org/10.1007/s13593-014-0269-7

Bertrand M, Blouin M, Barot S et al (2015b) Biocontrol of eyespot fungal disease on two winter wheat cultivars by an anecic earthworm (L. terrestris, L.). Appl Soil Ecol 96:33-41

Blouin M, Zuily-Fodil Y, Pham-Thi AT et al (2005) Belowground organism activities affect plant aboveground phenotype, inducing plant tolerance to parasites. Ecol Lett 8:202-208. https://doi.org/10.1111/ j.1461-0248.2004.00711.x

Blouin M, Barot S, Lavelle P (2006) Earthworms (Millsonia anomala, Megascolecidae) do not increase rice growth through enhanced nitrogen mineralization. Soil Biol Biochem 38:2063-2068. https://doi. org/10.1016/j.soilbio.2005.12.023

Blouin M, Hodson ME, Delgado EA et al (2013) A review of earthworm impact on soil function and ecosystem services. Eur J Soil Sci 64: 161-182. https://doi.org/10.1111/ejss.12025

Borenstein M, Hedges LV, Higgins JPT, Rothstein HR (2009) Introduction to meta-analysis. John Wiley \& Sons, Chichester

Bouché MB (1977) Stratégies lombriciennes. In: Lohm U, Persson T (eds) Soil organisms as components of ecosystems. Ecology Bulletin/NFR, Stockholm, pp 122-132

Brown GG, Pashanasi B, Villenave C et al (1999) Effects of earthworms on plant production in the tropics. In: Lavelle $\mathrm{P}$, Brussaard $\mathrm{L}$, Hendrix P (eds) Earthworm management in tropical agroecosystems. CAB International, Wallingford, pp 87-148

Bureau of International Recycling (BIR) (2008) Report on the environmental benefits of recycling. Brussels, Belgium

Chan KY, Baker GH, Conyers MK et al (2004) Complementary ability of three European earthworms (Lumbricidae) to bury lime and increase pasture production in acidic soils of South-Eastern Australia. Appl Soil Ecol 26:257-271. https://doi.org/10.1016/j.apsoil.2003.12.004

Chaoui H, Edwards CA, Brickner M et al (2002) Suppression of the plant diseases Pythium, Rhizoctonia, and Verticillium by vermicompost. Proc Bright Crop Prot Conf Pests Dis 2:711-715

Chaudhary DR, Bhandari SC, Shukla LM (2004) Role of vermicompost in sustainable agriculture - a review. Agric Rev 25:29-39

Cochran WG (1954) The combination of estimates from different experiments. Biometrics 10:101-129

Dignac M-F, Derrien D, Barré P et al (2017) Increasing soil carbon storage: mechanisms, effects of agricultural practices and proxies. A review. Agron Sust Dev 37:14. https://doi.org/10.1007/s13593017-0421-2

Dominguez J (2004) State-of-the-art and new perspectives on vermicomposting research. In: Earthworm ecology. CRC Press Boca Raton, FL, USA, pp 401-424

Drew MC, Saker LR, Ashley TW (1973) Nutrient supply and the growth of the seminal root system in barley: I. The effect of nitrate concentration on the growth of axes and laterals. J Exp Bot 24:1189-1202

Edixhoven JD, Gupta J, Savenije HHG (2014) Recent revisions of phosphate rock reserves and resources: reassuring or misleading? An indepth literature review of global estimates of phosphate rock reserves and resources. Earth Syst Dyn 5:491-507. https://doi.org/ 10.5194/esd-5-491-2014

Edwards CA, Dominguez J, Arancon NQ (2004) 18. The influence of vermicomposts on plant growth and pest incidence. In: Soil zoology for sustainable development in the 21st century. Cairo, Egypt, pp $397-420$ 
Edwards CA, Arancon NQ, Vasko-Bennett M et al (2010a) Effect of aqueous extracts from vermicomposts on attacks by cucumber beetles (Acalymna vittatum) (Fabr.) on cucumbers and tobacco hornworm (Manduca sexta) (L.) on tomatoes. Pedobiologia 53:141-148

Food Security Information Network (2017) Global report on food crises. World Food Program 2017

Godfray HCJ, Beddington JR, Crute IR et al (2010) Food security: the challenge of feeding 9 billion people. Science 327:812. https://doi. org/10.4337/9780857939388

Hedges LV, Gurevitch J, Curtis PS (1999) The meta-analysis of response ratios in experimental ecology. Ecology 80:1150-1156. https://doi. org/10.1890/0012-9658

Hoornweg D, Bhada-Tata P (2012) What a waste. A global review of solid waste management. World Bank Group, Washington DC

Jouquet P, Plumere T, Thuy DT et al (2010) The rehabilitation of tropical soils using compost and vermicompost is affected by the presence of endogeic earthworms. Appl Soil Ecol 46:125-133. https://doi.org/ 10.1016/j.apsoil.2010.07.002

Kummu M, De Moel H, Porkka M et al (2012) Lost food, wasted resources: global food supply chain losses and their impacts on freshwater, cropland, and fertiliser use. Sci Tot Environ 438:477-489

Lal R (2004) Soil carbon sequestration impacts on global climate change and food security. Science 304:1623-1627

Laossi KR, Ginot A, Noguera DC et al (2010) Earthworm effects on plant growth do not necessarily decrease with soil fertility. Plant Soil 328: 109-118. https://doi.org/10.1007/s11104-009-0086-y

Lavelle P, Melendez G, Pashanasi B, Schaefer R (1992) Nitrogen mineralization and reorganization in casts of the geophagous tropical earthworm Pontoscolex corethrurus (Glossoscolecidae). Biol Fertil Soils 14:49-53

Lazcano C, Domínguez J (2011) The use of vermicompost in sustainable agriculture: impact on plant growth and soil fertility. In: Miransari M (ed) Soil nutrients. Nova Science Publishers, Inc., Hauppauge, pp 123

Lee KE (1985) Earthworms their ecology and relationships with soils and land use. Academic Press, Sydney

Light RJ, Pillemer DB (1984) Summing up: the science of reviewing research. Harvard University Press, Cambridge

Milcu A, Puga-Freitas R, Ellison AM et al (2018) Genotypic variability enhances the reproducibility of an ecological study. Nat Ecol Evol 3194:279-287. https://doi.org/10.1038/s41559-017-0434-x

Murphy BW (2014) Soil organic matter and soil function-review of the literature and underlying data. Department of the Environment, Canberra, Australia

Puga-Freitas R, Blouin M (2015) A review of the effects of soil organisms on plant hormone signalling pathways. Environ Exp Bot 114:104 116

Puga-Freitas R, Abbad S, Gigon A et al (2012a) Control of cultivable IAA-producing bacteria by the plant Arabidopsis thaliana and the earthworm Aporrectodea caliginosa. Appl Environ Soil Sci 2012:14. https://doi.org/10.1155/2012/307415

Puga-Freitas R, Barot S, Taconnat L et al (2012b) Signal molecules mediate the impact of the earthworm Aporrectodea caliginosa on growth, development and defence of the plant Arabidopsis thaliana. PLoS One 7:e49504

Puga-Freitas R, Belkacem L, Barot S et al (2016) Ability of the earthworm Aporrectodea caliginosa to reduce the severity of take-all disease of wheat. Eur J Plant Pathol 144:155-165

Richter SH, Garner JP, Wurbel H (2009) Environmental standardization: cure or cause of poor reproducibility in animal experiments? Nat Meth 6:257-261. dx.doi.org. https://doi.org/10.1038/nmeth.1312

Robinson D (1994) The responses of plants to non-uniform supplies of nutrients. New Phytol 127:635-674

Rosenberg MS, Adams DC, Gurevitch J (2000) MetaWin: statistical software for meta-analysis. Sinauer Associates Sunderland, Massachusetts, USA
Rosenthal R (1979) The "file drawer problem" and tolerance for null results. Psychol Bull 86:638-641

Shiralipour A, McConnell DB, Wayne HS (1992) Uses and benefits of MSW compost: a review and an assessment. Biomass Bioenergy 3: 267-279

Szabo L, Soria A, Forsström J et al (2009) A world model of the pulp and paper industry: demand, energy consumption and emission scenarios to 2030. Environ Sci Pol 12:257-269. https://doi.org/10.1016/j. envsci.2009.01.011

Tilman D, Fargione J, Wolff B et al (2001) Forecasting agriculturally driven global environmental change. Science 292:281-284. https:// doi.org/10.1126/science.1057544

van Groenigen JW, Lubbers IM, Vos HMJ et al (2014) Earthworms increase plant production: a meta-analysis. Sci Rep 4:6365. https://doi. org/10.1038/srep06365

Vitousek PM, Aber JD, Howarth RW et al (1997) Human alteration of the global nitrogen cycle: sources and consequences. Ecol Appl 7:737750

Wilson BJ (1988) A review of evidence on the control of shoot:root ratio, in relation to models. Ann Bot 61:433-449

\section{Further reading}

Ali M, Griffiths AJ, Williams KP, Jones DL (2007) Evaluating the growth characteristics of lettuce in vermicompost and green waste compost. Eur J Soil Biol 43:316-319. https://doi.org/10.1016/j.ejsobi.2007. 08.045

Allardice RP, Kapp C, Botha A, Valentine A (2015) Optimizing vermicompost concentrations for the $\mathrm{N}$ cutrition and production of the legume Lupinus angustifolius. Compost Sci Util 23:217-236. https://doi.org/10.1080/1065657X.2015.1038399

Andreev N, Ronteltap M, Lens PNL et al (2016) Lacto-fermented mix of faeces and bio-waste supplemented by biochar improves the growth and yield of corn (Zea mays L.). Agric Ecosyst Environ 232:263272. https://doi.org/10.1016/j.agee.2016.08.012

Arancon NQ, Edwards CA, Bierman P et al (2003a) Effects of vermicomposts on growth and marketable fruits of field-grown tomatoes, peppers and strawberries. Pedobiologia 47:731-735. https:// doi.org/10.1078/0031-4056-00251

Arancon NQ, Lee S, Edwards CA, Atiyeh R (2003b) Effects of humic acids derived from cattle, food and paper-waste vermicomposts on growth of greenhouse plants. Pedobiologia 47:741-744. https://doi. org/10.1078/0031-4056-00253

Arancon NQ, Edwards CA, Lee S, Byrne R (2006) Effects of humic acids from vermicomposts on plant growth. Eur J Soil Biol 42:65-69. https://doi.org/10.1016/j.ejsobi.2006.06.004

Arancon NQ, Edwards CA, Babenko A et al (2008) Influences of vermicomposts, produced by earthworms and microorganisms from cattle manure, food waste and paper waste, on the germination, growth and flowering of petunias in the greenhouse. Appl Soil Ecol 39:91-99. https://doi.org/10.1016/j.apsoil.2007.11.010

Arancon NQ, Pant A, Radovich T et al (2012) Seed germination and seedling growth of tomato and lettuce as affected by vermicompost water extracts (teas). HortScience 47:1722-1728

Aremu AO, Kulkarni MG, Bairu MW et al (2012) Growth stimulation effects of smoke-water and vermicompost leachate on greenhouse grown-tissue-cultured "Williams" bananas. Plant Growth Regul 66: 111-118. https://doi.org/10.1007/s10725-011-9634-6

Aremu AO, Masondo NA, Van Staden J (2014) Physiological and phytochemical responses of three nutrient-stressed bulbous plants subjected to vermicompost leachate treatment. Acta Physiol Plant 36: 721-731. https://doi.org/10.1007/s11738-013-1450-3

Argüello JA, Seisdedos L, Goldfarb MCD et al (2013) Anatomophysiological modifications induced by solid agricultural 
waste (vermicompost) in lettuce seedlings (Lactuca sativa L.). Phyton 82:289-295

Arthur GD, Aremu AO, Kulkarni MG, Van Staden J (2012) Vermicompost leachate alleviates deficiency of phosphorus and potassium in tomato seedlings. HortScience 47:1304-1307

Atiyeh RM, Domínguez J, Subler S, Edwards CA (2000) Changes in biochemical properties of cow manure during processing by earthworms (Eisenia andrei, Bouché) and the effects on seedling growth. Pedobiologia 44:709-724. https://doi.org/10.1078/S0031-4056(04) 70084-0

Atiyeh RM, Subler S, Edwards CA et al (2000b) Effects of vermicomposts and composts on plant growth in horticultural container media and soil. Pedobiologia 44:579-590. https://doi.org/10. 1078/S0031-4056(04)70073-6

Atiyeh RM, Edwards CA, Subler S, Metzger JD (2001) Pig manure vermicompost as a component of a horticultural bedding plant medium : effects on physicochemical properties and plant growth. Bioresour Technol 78:11-20. https://doi.org/10.1016/S09608524(00)00172-3

Atiyeh RM, Arancon NQ, Edwards CA, Metzger JD (2002) The influence of earthworm-processed pig manure on the growth and productivity of marigolds. Bioresour Technol 81:1-6. https://doi.org/ 10.1016/S0960-8524(01)00122-5

Bharti N, Barnawal D, Shukla S et al (2016a) Integrated application of Exiguobacterium oxidotolerans, Glomus fasciculatum, and vermicompost improves growth, yield and quality of Mentha arvensis in salt-stressed soils. Ind Crop Prod 83:717-728. https:// doi.org/10.1016/j.indcrop.2015.12.021

Bharti N, Barnawal D, Wasnik K et al (2016b) Co-inoculation of Dietzia natronolimnaea and Glomus intraradices with vermicompost positively influences Ocimum basilicum growth and resident microbial community structure in salt affected low fertility soils. Appl Soil Ecol 100:211-225. https://doi.org/10.1016/j.apsoil.2016.01.003

Croria-Cayupan YS, Sanchez de Pinto MI, Azucuena Nazareno M (2009) Variations in bioactive substance contents and crop yields of lettuce (Lactuca sativa L.) cultivated in soils with different fertilization treatments. J Agric Food Chem 57:10122-10129. https://doi.org/ $10.1021 / \mathrm{jf} 903019 \mathrm{~d}$

de Souza MEP, de Carvalho AMX, de Cássia Deliberali D et al (2013) Vermicomposting with rock powder increases plant growth. Appl Soil Ecol 69:56-60. https://doi.org/10.1016/j.apsoil.2013.01.016

Doan TT, Ngo PT, Rumpel C et al (2013) Interactions between compost, vermicompost and earthworms influence plant growth and yield: a one-year greenhouse experiment. Sci Hortic 160:148-154. https:// doi.org/10.1016/j.scienta.2013.05.042

Edwards CA, Arancon NQ, Vasko-Bennett M et al (2010b) Suppression of green peach aphid (Myzus persicae) (Sulz.), citrus mealybug (Planococcus citri) (Risso), and two spotted spider mite (Tetranychus urticae) (Koch.) attacks on tomatoes and cucumbers by aqueous extracts from vermicomposts. Crop Prot 29:80-93. https://doi.org/10.1016/j.cropro.2009.08.011

Ersahin YS, Haktanir K, Yanar Y (2009) Vermicompost suppresses Rhizoctonia solani Kühn in cucumber seedlings. J Plant Dis Prot 116:182-188. https://doi.org/10.1007/2FBF03356308

Fernández-Gómez MJ, Quirantes M, Vivas A, Nogales R (2012) Vermicomposts and/or arbuscular mycorrhizal fungal inoculation in relation to metal availability and biochemical quality of a soil contaminated with heavy metals. Water Air Soil Pollut 223:27072718. https://doi.org/10.1007/s11270-011-1061-9

García AC, Santos LA, de Souza LGA et al (2016) Vermicompost humic acids modulate the accumulation and metabolism of ROS in rice plants. J Plant Physiol 192:56-63. https://doi.org/10.1007/s13593015-0307-0

Guo L, Wu G, Li C et al (2015) Vermicomposting with maize increases agricultural benefits by 304\%. Agron Sust Dev 35:1149-1155. https://doi.org/10.1007/s13593-015-0307-0
Gupta M, Srivastava PK, Niranjan A, Tewari SK (2016) Use of a bioaugmented organic soil amendment in combination with gypsum for Withania somnifera growth on sodic soil. Pedosphere 26:299 309. https://doi.org/10.1016/S1002-0160(15)60044-3

Jayakumar M, Sivakami T, Ambika D, Karmegam N (2013) Effect of Turkey litter (Meleagris gallopavo L.) vermicompost on growth and yield characteristics of paddy, Oryza sativa (ADT-37). African J Biotechnol 10:15295-15304. https://doi.org/10.4314/ajb.v10i68

Kandari L, Kulkarni M, van Staden J (2011) Vermicompost leachate improves seedling emergence and vigour of aged seeds of commercially grown Eucalyptus species. South For J For Sci 73:117-122. https://doi.org/10.2989/20702620.2011.610923

Karlsons A, Osvalde A, Andersone-Ozola U, Ievinsh G (2016) Vermicompost from municipal sewage sludge affects growth and mineral nutrition of winter rye (Secale cereale) plants. J Plant Nutr 39:765-780. https://doi.org/10.1080/01904167.2015.1087566

Kumar R, Kaur I, Bhatnagar AK (2013) Enhancing soil health and productivity of Lycopersicon esculentum Mill. using Sargassum johnstonii Setchell \& Gardner as a soil conditioner and fertilizer. J Appl Phycol 25:1225-1235. https://doi.org/10.1007/s10811-0129933-y

Kumar R, Shamet GS, Alam NM, Jana C (2016) Influence of growing medium and seed size on germination and seedling growth of Pinus gerardiana Wall. Compost Sci Util 24:98-104. https://doi.org/10. 1080/1065657X.2015.1048906

Larchevêque M, Desrochers A, Bussière B et al (2013) Revegetation of non-acid-generating, thickened tailings with boreal trees: a greenhouse study. J Environ Qual 42:351-360. https://doi.org/10.2134/ jeq2012.0111

Lazcano C, Revilla P, Malvar RA, Domínguez J (2011) Yield and fruit quality of four sweet corn hybrids (Zea mays) under conventional and integrated fertilization with vermicompost. J Sci Food Agric 91: 1244-1253. https://doi.org/10.1002/jsfa.4306

Lazcano C, Gómez-Brandón M, Revilla P, Domínguez J (2013) Shortterm effects of organic and inorganic fertilizers on soil microbial community structure and function. Biol Fertil Soils 49:723-733. https://doi.org/10.1007/s00374-012-0761-7

Levinsh G (2011) Vermicompost treatment differentially affects seed germination, seedling growth and physiological status of vegetable crop species. Plant Growth Regul 65:169-181. https://doi.org/10.1007/ s10725-011-9586-x

Mahmoud EK, Ibrahim MM (2012) Effect of vermicompost and its mixtures with water treatment residuals on soil chemical properties and barley growth. J Soil Sci Plant Nutr 12:431-440. https://doi.org/10. 4067/S0718-95162012005000005

Mani D, Kumar C, Patel NK (2016) Integrated micro-biochemical approach for phytoremediation of cadmium and lead contaminated soils using Gladiolus grandiflorus L cut flower. Ecotoxicol Environ Saf 124:435-446. https://doi.org/10.1016/j.ecoenv.2015. 11.016

Masondo NA, Kulkarni MG, Rengasamy KRR et al (2016) Effect of vermicompost leachate in Ceratotheca triloba under nutrient deficiency. Acta Physiol Plant 38:236. https://doi.org/10.1007/s11738016-2252-1

Molina-Maldonado JR, Salvador-Figueroa M, Montes-Molina JA et al (2012) Vermicompost effect on growth and production of secondary metabolites in Ardisia escallonioides. Gayana Bot 69:82-88

Morales-Corts MR, Gómez-Sánchez MÁ, Pérez-Sánchez R (2014) Evaluation of green/pruning wastes compost and vermicompost, slumgum compost and their mixes as growing media for horticultural production. Sci Hortic (Amsterdam) 172:155-160. https://doi. org/10.1016/j.scienta.2014.03.048

Niranjan RK, Pal A, Gupta HK et al (2010) Performance of different vermicomposts on yield and yield components of Mungbean (Vigna radiata L.) in major soils of Bundelkhand region, India. J 
Ecophysiol Occup Heal 10:61-70. https://doi.org/10.18311/jeoh/ 2010/18262

Oo AN, Iwai CB, Saenjan P (2015) Soil properties and maize growth in saline and nonsaline soils using cassava-industrial waste compost and vermicompost with or without earthworms. L Degrad Dev 26: 300-310. https://doi.org/10.1002/ldr.2208

Pandey V, Patel A, Patra DD (2016) Integrated nutrient regimes ameliorate crop productivity, nutritive value, antioxidant activity and volatiles in basil (Ocimum basilicum L.). Ind Crop Prod 87:124-131. https://doi.org/10.1002/ldr.2208

Pant AP, Radovich TJK, Hue NV et al (2009) Vermicompost extracts influence growth, mineral nutrients , phytonutrients and antioxidant activity in pak choi (Brassica rapa cv. Bonsai, Chinensis group) grown under vermicompost and chemical fertiliser. J Sci Food Agric 89:2383-2392. https://doi.org/10.1002/jsfa.3732

Pant AP, Radovich TJK, Hue NV, Miyasaka SC (2012) Pak Choi (Brassica rapa, Chinensis group) yield, phytonutrient content, and soil biological properties as affected by vermicompost-to-water ratio used for extraction. Hortic Sci 47:395-402

Patel D, Saraf M (2014) Comparative study of different soil amendments and microbes for integrated nutrient management and growth promotion of Jatropha curcas. J Plant Nutr 37:2209-2226. https://doi. org/10.1080/01904167.2014.920382

Roy S, Arunachalam K, Kumar B, Arunachalam A (2010) Effect of organic amendments of soil on growth and productivity of three common crops viz. Zea mays, Phaseolus vulgaris and Abelmoschus esculentus. Appl Soil Ecol 45:78-84. https://doi.org/ 10.1016/j.apsoil.2010.02.004

Sainz MJ, Taboada-Castro MT, Vilariño A (1998) Growth, mineral nutrition and mycorrhizal colonization of red clover and cucumber plants grown in a soil amended with composted urban wastes. Plant Soil 205:85-92. https://doi.org/10.1023/A:1004357330318

Sangwan P, Garg VK, Kaushik CP (2010) Growth and yield response of marigold to potting media containing vermicompost produced from different wastes. Environmentalist 30:123-130. https://doi.org/10. 1007/s10669-009-9251-3

Sharif F, Danish MU, Ali AS et al (2016) Salinity tolerance of earthworms and effects of salinity and vermi amendments on growth of Sorghum bicolor. Arch Agron Soil Sci 62:1169-1181. https://doi. org/10.1080/03650340.2015.1132838
Shen T, Wang C, Yang H et al (2016) Identification, solid-state fermentation and biocontrol effects of Streptomyces hygroscopicus B04 on strawberry root rot. Appl Soil Ecol 103:36-43. https://doi.org/10. 1016/j.apsoil.2016.02.016

Singh R, Soni SK, Awasthi A, Kalra A (2012) Evaluation of vermicompost doses for management of root-rot disease complex in Coleus forskohlii under organic field conditions. Austral Plant Pathol 41:397-403. https://doi.org/10.1007/s13313-012-0134-6

Singh S, Kulkarni MG, Van Staden J (2014) Biochemical changes associated with gibberellic acid-like activity of smoke-water, karrikinolide and vermicompost leachate during seedling development of Phaseolus vulgaris L. Seed Sci Res 24:63-70. https://doi. org/10.1017/S0960258513000408

Song X, Liu M, Wu D et al (2015) Interaction matters: synergy between vermicompost and PGPR agents improves soil quality, crop quality and crop yield in the field. Appl Soil Ecol 89:25-34. https://doi.org/ 10.1016/j.apsoil.2015.01.005

Suthar S (2009) Impact of vermicompost and composted farmyard manure on growth and yield of garlic (Allium sativum L.) field crop. Int J Plant Prod 3:27-38

Tejada M, Benitez C (2011) Organic amendment based on vermicompost and compost: differences on soil properties and maize yield. Waste Manag Res 29:1185-1196. https://doi.org/10.1177/ $0734242 X 10383622$

Tejada M, Gonzalez JL (2009) Application of two vermicomposts on a rice crop: effects on soil biological properties and rice quality and yield. Agron J 101:336-344. https://doi.org/10.2134/agronj2008. 0211

Verma SK, Pankaj U, Khan K et al (2016) Bioinoculants and vermicompost improve Ocimum basilicum yield and soil health in a sustainable production system. CLEAN-Soil, Air, Water 44:686693. https://doi.org/10.1002/clen.201400639

Zaller JG (2007) Vermicompost in seedling potting media can affect germination, biomass allocation, yields and fruit quality of three tomato varieties. Eur J Soil Biol 43:332-336. https://doi.org/10. 1016/j.ejsobi.2007.08.020

Publisher's note Springer Nature remains neutral with regard to jurisdictional claims in published maps and institutional affiliations. 